\title{
Information Sources, Awareness, and Perception Levels About Climate Change Impacts: A Case Study on Florida Stakeholders
}

\author{
Vassiki Sanogo ${ }^{1, \dagger}$, Julie Harrington ${ }^{2, \dagger}$, Zafar Siddiqui ${ }^{2}$ \\ ${ }^{1}$ Department of Pharmaceutical Outcomes and Policy, University of Florida, Gainesville, United States of America \\ ${ }^{2}$ Center for Economic Forecasting and Analysis, Florida State University, Tallahassee, United States of America \\ Email address: \\ vsanogo@hotmail.fr (V. Sanogo), jharrington@cefa.fsu.edu (J. Harrington), siddiquizr@yahoo.com (Z. Siddiqui) \\ ${ }^{\dagger}$ Vassiki Sanogo and Julie Harrington are co-first authors.
}

\section{To cite this article:}

Vassiki Sanogo, Julie Harrington, Zafar Siddiqui. Information Sources, Awareness, and Perception Levels About Climate Change Impacts: A Case Study on Florida Stakeholders. International Journal of Economy, Energy and Environment. Vol. 3, No. 2, 2018, pp. 6-20. doi: $10.11648 /$ j.ijeee.20180302.11

Received: May 10, 2018; Accepted: May 31, 2018; Published: August 1, 2018

\begin{abstract}
There is a growing body of literature in sustainability that analyzes stakeholder perceptions of climate change and associated impacts. However, significant research has not been documented from the spectrum of Social Network Analysis (SNA) and Survey Analysis using a chi-square test for homogeneity, that examine local and regional (State-level) stakeholders' climate-impact perceptions. In this paper, authors explore the types of climate-related information sources that local, regional, and non-profit stakeholders use. The authors also develop and examine the map of the flow of climate-related impact perceptions. Additionally, the researchers determine whether there are observable patterns in the stakeholders' approaches for securing climate-related information. The Social Network Analysis results present the relationship and the map of climateimpact perceptions among critical stakeholders in Florida that are involved in climate issues. Comparing and examining the SNA results with that chi-square constitute the final finding of the network pattern.
\end{abstract}

Keywords: Climate Change Impacts, Perceptions, Survey, Chi-square Test, Social Network Analysis, Florida

\section{Introduction}

Climate change has become the concern of current times a concept that carries profound social, political and environmental connotations. These overtones are further stressed by the emerging and substantial scientific consensus that anthropogenic climate change may cause irreversible damages to the fragile ecosystem [1-7]. Extensive research is being done to determine the extent of climate change and the proportion of variation caused by anthropogenic forces, potential impacts on drought, sea level, local weather and hurricanes [8]. General Circulation Models (GCMs) provide us with a reliable estimate of mean annual global temperature. However, the precipitation and temperature information at the regional and local level are often reported to be unreliable [8].

Growing public awareness and interest in the causes and impacts of climate change led to increasing research in various aspects of climate change. Additionally, the issues of climate change, its impact, assessment, and management of its impact have taken salient positions in the public policy agendas of local, regional (state) as well as national governments. The understanding of climate change and its impact may affect individuals' decisions, lifestyles, voting trends and their inclination to back the policy action regarding climate change [9].

Policy action depends in part on how climate change and its impact are perceived and assessed by the public in general, and by the stakeholders, in particular. A sufficient buildup of extreme events may impact the frame of reference of stakeholders. Although local and regional impacts are of considerable interest to regional stakeholders, their ability to react by the adoption of policy and practice depends mainly on their frame of reference concerning their understanding of decision-making systems and policy [10]. In the U.S context, states and local governments have been much more active in 
pursuing climate-related policies ${ }^{1}$, whereas federal governments' actions have remained comparatively ad hoc due to partisan divide on the issue of climate change.

The state of Florida - being a peninsula surrounded on both sides by warm oceans is particularly at risk to adverse climatic hazards of various types that may result from global warming in the near and distant future. The stakeholders perceived this threat in different ways depending on whether they resort to similar or different sources of information, and their awareness levels about the phenomenon of climate change. The dynamics of social networks among the stakeholders would further mitigate the gap in the perceptions [11]. The authors examined the stakeholders' perceptions of the impact of climate change under the hypotheses that local, regional, and non-profit stakeholders that are sharing similar information sources and similar levels of awareness of climate change would have parallel perceptions of the impact of climate change, according to the dynamics of social networks.

Throughout this research, the authors sought to answer the following questions: do Florida stakeholders resort to similar sources of data and information? Do Florida stakeholders have similar awareness levels about the phenomenon of climate change? And what are the dynamics of the Florida stakeholders' social networks?

Accordingly, authors employed a two-stage approach to this research; the first stage consisted of a survey administered to the stakeholders, while the second stage involved the use of Social Network Analysis (SNA) through the UCINET [12]. The findings of the first stage are further used to inform the SNA. The authors examined the stakeholders' climate-impact perceptions and hypothesized that local, regional, and non-profit stakeholders that share similar climate-impact perceptions use the same information sources.

\section{Materials and Methods}

A two-stage approach was used to address the research questions: a survey and a Social Network Analysis:

Survey Analysis. Usually, survey respondents are asked about their practices, beliefs, or situations (see supplement documents) from a random sample of subjects in field settings. However, for this research, in a closed network, stakeholders have been selected by convenience sample. Thereby, these selections operated among the Florida key stakeholders, climate-related organizations. However, each stakeholder had the same chance of being chosen, but stakeholders of different agencies would have had different probabilities of being selected, meaning that one may have more stakeholders from one institution and fewer from another. Data collected from this survey were converted into matrices, then used as input for analyzing the dynamics of Florida key stakeholders' perception of climate change risks. The survey data were analyzed using a statistical tool of a

1 McPhaden J. M. et al., 1998; Dwayne E. P. et al., 2004; Kohut J. et al., 2012 chi-squared test for homogeneity ${ }^{2}$, in the context of categorical data (see the supplement document on data management).

Social Network Analysis. The SNA built upon studies [1314], is a well-known tool for its descriptive and analytic benefits. Using SNA based on the relational or social input data, collected in various formats [15], allowed us to identify the pattern of Florida key stakeholders, who perceive climate change as a risk. A software package (UCINET) was used, for the analyses.

Further details about the rationale of combining these two approaches are provided, in the following sections. For the purpose of this paper, stakeholder has been defined as any organization (private or public, for-profit or non-profit) involved actively in climate change-related issues. This definition also reveals the boundaries of the survey population. Public refers to federal, state, or local government or agencies. Private describes any organization without a public role, which provides goods and services, and is owned by individuals.

\subsection{Survey}

Researchers use a range of methods to assess the climaterelated perceptions, values, expectations, awareness, and knowledge of stakeholders. For example, interviews, surveys, and focus groups are techniques for gathering data to shape decision support systems [16]. Among these validated approaches, the authors designed a survey instrument to collect data on information sources, awareness levels, and the perception of climate change impacts in Florida. The target population in this research are Florida's key stakeholders including public, private, and researchers involved actively in climate change issues. The research team's selected sample included 13 local and regional Florida stakeholders impacted by climate change. Among these individuals, two represented the same institution. The authors chose the participants to cover as much of a broad spectrum of critical stakeholders; geographically, sectorial, and socioeconomically. The employees at the managerial level represented stakeholders. The survey small sample size was based on the purpose of this research, which intends to target the closed network of the key stakeholders concerned by climate change.

In 2011, the authors developed and distributed a survey questionnaire to the climate-related vital stakeholders. Each questionnaire captured information about stakeholders' characteristics, climate-related information and public or private organizations, climate change projections for Florida, and climate and weather information requirements. The research team administered questionnaires to leaders and other key individuals in public and private institutions that develop, disseminate, or use climate information, as well as those that assess vulnerability or conduct programs aimed at the adaptation to, and mitigation of, climate change and sea level rise. Survey questions were electronically distributed,

2 Robert G. D. Steel and James H. Torrie, 1980 "Principles and Procedures of Statistics: A Biometrical Approach" Second Edition, pp 477-478 
during the period ranging from October 15, 2012, to November 19, 2012. The authors sent a relatively short email survey to stakeholders, asking them to value the attributes of the survey questions for measuring these constructs.

For the data analysis purposes, the questionnaires were reorganized into ten dimensions to measure stakeholders' perceptions about climate change impacts. These dimensions were IWDO: Importance of weather in daily operation; I-CI: Importance of climate information; CIU: Climate information usage; I-SV: Importance of seasonal variability; IWB: Impact of weather on business; I-SLR: Importance of SLR; I-CC: Importance of climate change; CFC: Changes in Florida climate; IFCCB: Impact of Florida's climate change on business; and EEWB: Effect of extreme weather on business. The stakeholders' perceptions about climate impacts were measured against the dimensions as mentioned above using a five-attribute Likert scale: "extremely important," "somewhat important," "neutral," "somewhat unimportant," and "not at all important." The qualitative responses to the survey questionnaires were converted, into quantitative values using a similar 5-point descending scale of the Likert scale. Specifically, the scale attribute (used in the survey) "extremely important" was assigned the score five while the attribute "not at all important" was assigned the score 1 . These scores were further used to create matrices that: 1) served to identify stakeholders that share similar information sources and perceptions about climate change impacts, and; 2) served as a basis of the SNA using the UCINET Software.

\subsection{Social Network Analysis}

Over the last decade, there has been an increase in climate learning networks [17]. The broad aim of these networks is to create a space for knowledge exchange, learning, and monitoring to support the stakeholders and extension professionals as they prepare for an uncertain future within the context of changing climate. These networks provide a venue to build and strengthen relationships among participants involved in research, outreach, and practice. SNA was used to map the relationship among Florida stakeholders involved in climate issues, based on the climate impact perceptions of these stakeholders. These links constitute the theory behind the Social Network Analysis (SNA).

SNA refers to a "toolkit" of methods that allows researchers to statistically describe, quantify, and compare the social relationships of individuals in a group [18-19]. SNA is based, on two notions: the node or vertex, and the link or edge or tie. In this study, each node represents a stakeholder, while the links represent the connections they have with their information sources, on the one hand, and their climate impact perceptions, on the other hand.

In this study, an SNA was conducted based on the survey results. The matrix from the survey results is imported, into UCINET. Next, SNA diagrams are generated, as a means to represent relationships and informational flows among stakeholders. The SNA diagrams are based, on the Eigen sensitive approach, which examines the dynamics among stakeholders. Additionally, two centrality approaches were used to identify the core of the network (i.e., stakeholders in the center of the network): 1) the betweenness centrality, and; 2) the eigenvector centrality. The identification of the core of the network will facilitate the authors testing the hypothesis that Florida stakeholders having similar climate impact perceptions about climate change use identical climaterelated information sources.

\section{Results}

\subsection{Survey}

The survey response rate was estimated to be $83 \%$. Among the 13 local and regional stakeholders surveyed (Table 1), 12 responded. Also, the distribution of Florida key stakeholders, susceptible to the impacts associated with a changing climate are shown, in Figure 1. The data collection covers several sectors, including the social ecosystem, agriculture, energy utility, water, development, industry and natural ecosystems. Furthermore, data has been collected at various interest levels, including, the state agency, local government, private, academia, and other. Table 1 shows the coding and description of the Florida key stakeholders.

Table 1. Key Stakeholders in a Florida Climate Network \& Their Descriptions.

\begin{tabular}{lll}
\hline Coding & Description & Individual Stakeholder \\
\hline SLS1 & State Level Stakeholder & Forest Service (Director level) \\
SLS2 & State Level Stakeholder & Department of Transportation \\
SLS3 & State Level Stakeholder & Florida State University \\
SLS4 & State Level Stakeholder & Fish and Wildlife Conservation Commission \\
SLS5 & State Level Stakeholder & Forest Service (Meteorologist) \\
SLS6 & State Level Stakeholder & Department of Environmental Protection \\
LS1 & Local Level Stakeholder & City Environmental Engineer \\
LS2 & Local Level Stakeholder & County: In-charge Resource Stewardship \\
LS3 & Local Level Stakeholder & County: Transportation \\
NPS1 & Non-profit Stakeholder & Public interest law \\
NPS2 & Non-profit Stakeholder & Public interest law \\
NPS3 & Non-profit Stakeholder & Public interest law \\
ELS & Environmental Legal Services & Law Firm \\
\hline
\end{tabular}




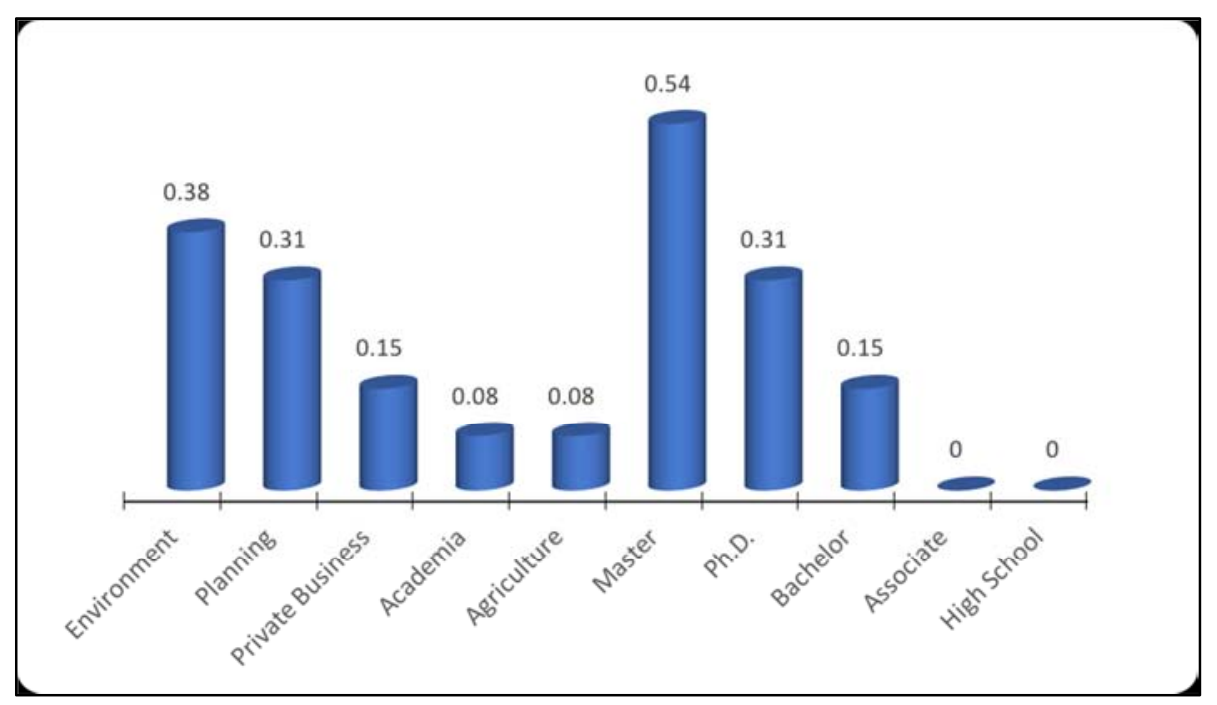

Figure 1. Key Stakeholders Distributions by Category.

\subsubsection{Florida Stakeholders' Perceptions About Climate Change Impacts}

The key stakeholders' perceptions about climate change were captured using factual questions. These revealed a level of perception that ranged between 2.75 and 4.14 out of 5 (see Figure 2).

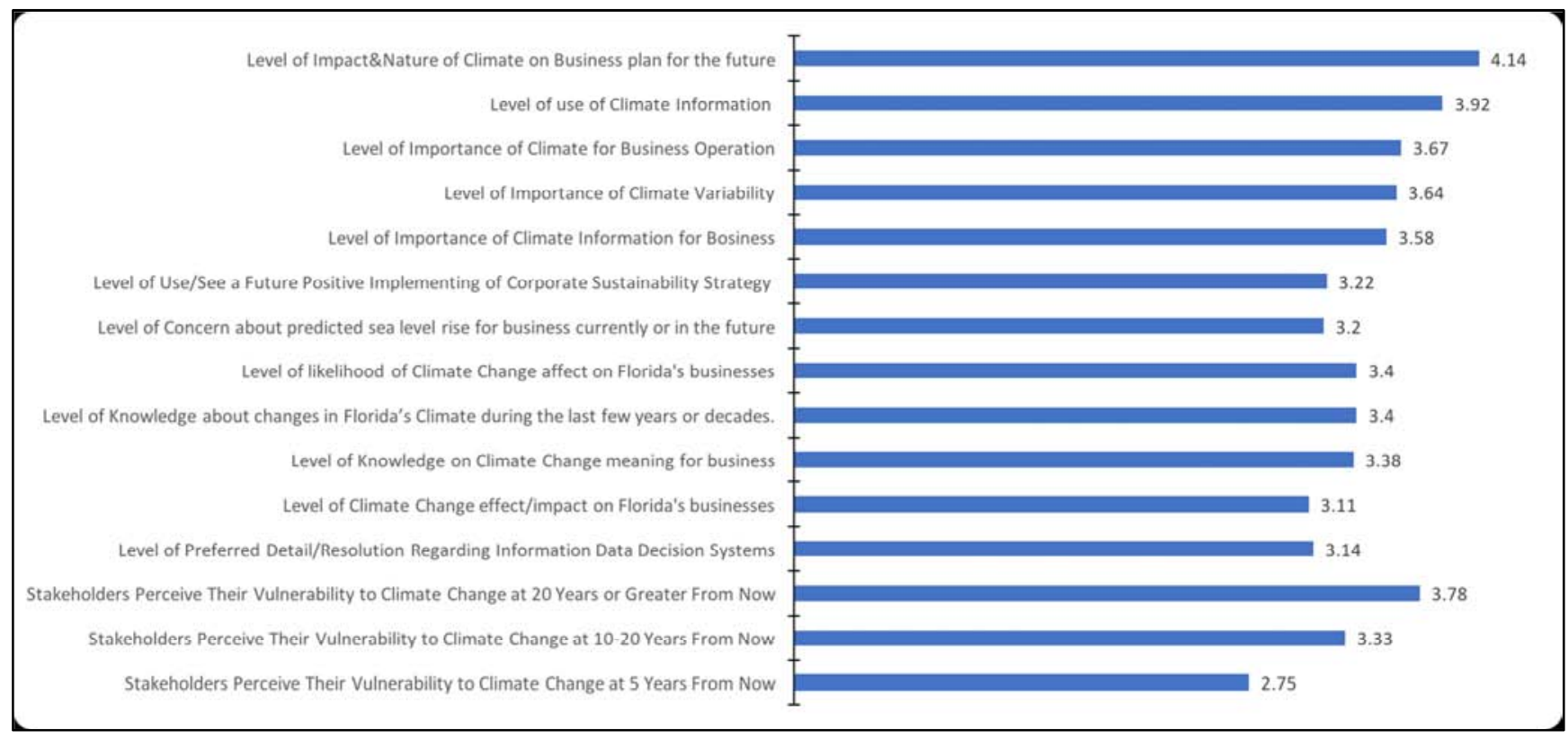

Figure 2. Factors of Florida key stakeholders' perceptions about climate change risks.

However, the stakeholders' opinions were that the climate change impacts are more likely to be harmful to their businesses (see Figure 3). The following acronyms seen in Table 2 were used to represent the stakeholders involved in this study: SLS for State Level Stakeholder, LS for Local Level Stakeholder, NPS for Non-profit Stakeholder, and ELS for Environmental Legal Services.

Table 2. Matrix of Stakeholders Versus Climate-Impact Perceptions, Data Sources, and Awareness Levels.

\begin{tabular}{lllllllllll}
\hline & IWDO & I-CI & CIU & I-SV & IWB & I-SLR & I-CC & CFC & IFCCB & EEWB \\
\hline SLS1 & 5 & 5 & 4 & 5 & 4 & 3 & 5 & 4 & 4 \\
SLS2 & 4 & 4 & 4 & 4 & & & & & \\
SLS3 & 3 & 3 & 5 & 4 & 4 & 4 & 4 & 1 & \\
SLS4 & 4 & 4 & 4 & 4 & & 5 & & & \\
SLS5 & 5 & 4 & 5 & 4 & 4 & 1 & 4 & 3 & 3 & 5 \\
SLS6 & 4 & 4 & 4 & & 3 & 4 & 3 & 4 & 4 \\
\hline
\end{tabular}




\begin{tabular}{lllllllllll}
\hline & IWDO & I-CI & CIU & I-SV & IWB & I-SLR & I-CC & CFC & IFCCB & EEWB \\
\hline LS1 & 3 & 2 & 2 & 3 & & 2 & 2 & 3 & 3 & 3 \\
LS2 & 2 & 2 & 2 & 2 & & 2 & 2 & 4 & 2 & 2 \\
LS3 & 5 & 4 & 4 & 4 & 4 & 1 & 3 & 3 & 2 & 2 \\
NPS2 & 3 & 4 & 5 & 4 & 5 & 5 & & 5 & 4 & 4 \\
NPS3 & 2 & 4 & 4 & 1 & & & & 3 & 2 & 2 \\
ELS & 4 & 3 & 4 & 5 & 5 & 5 & 4 & 4 & 4 & 4 \\
\hline
\end{tabular}

Values represent the corresponding perception score attributed by each stakeholder

IWDO: Importance of weather in daily operation; I-CI: Importance of climate information; CIU: Climate information usage; I-SV: Importance of seasonal variability; IWB: Impact of weather on business; I-SLR: Importance of Sea Level Rise; I-CC: Importance of climate change; CFC: Changes in Florida climate; IFCCB: Impact of Florida's climate change on business; and EEWB: Effect of extreme weather on business.

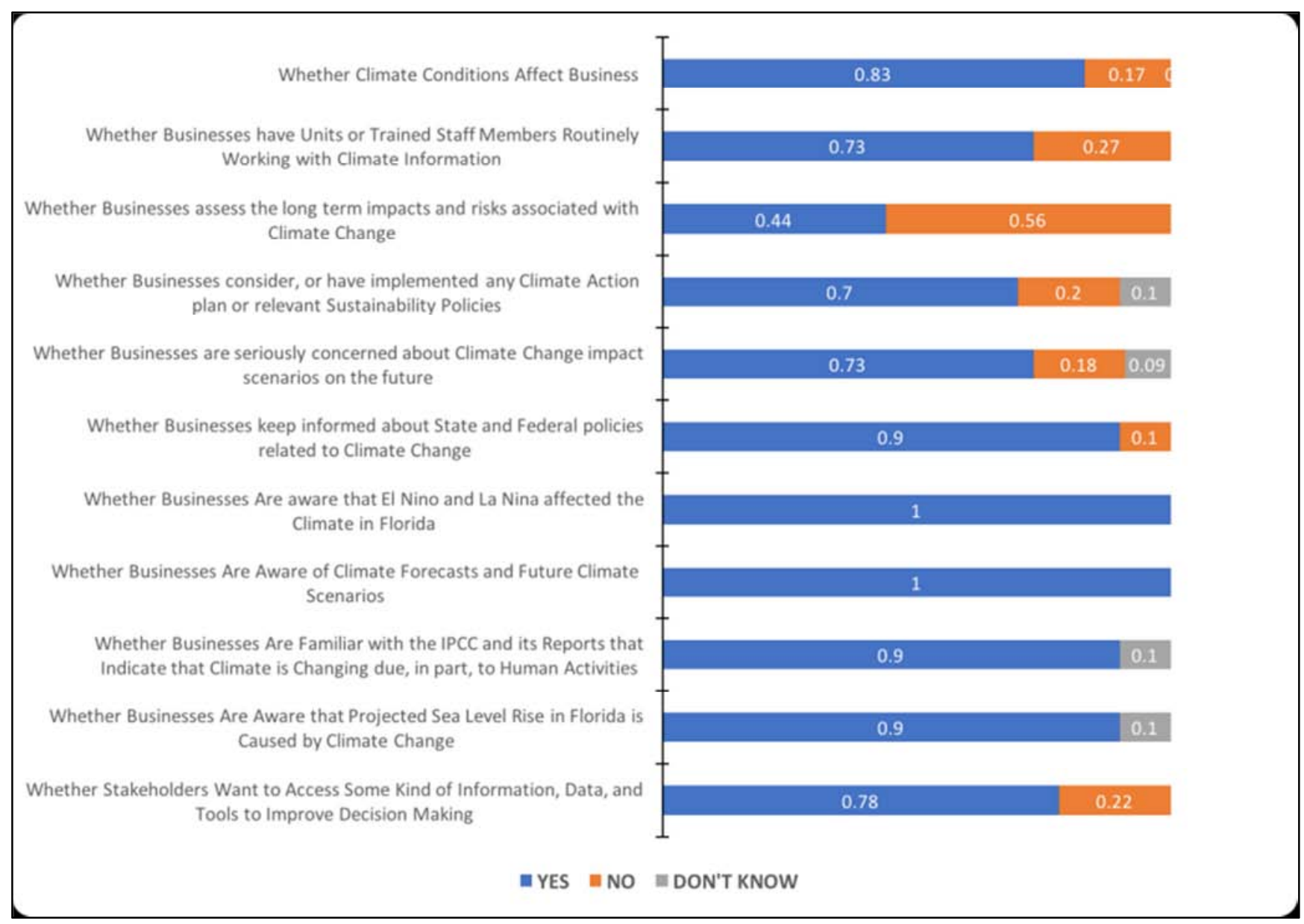

Figure 3. Factors of Florida key stakeholders' opinions about climate change risks.

The Chi-Square test for homogeneity performed at the perception level, it revealed that the stakeholders SLS1, SLS3, SLS5, LS1, LS2, LS3, NPS2, NPS3, ELS are those who were sharing similar climate change-related risks perceptions in term of statistical significance (see Table 3).

Table 3. Results of a Chi-Square Test of Homogeneity among Stakeholders in the Climate Change Risks Perception.

\begin{tabular}{lllll}
\hline & Df. & Critical Values of Chi-Square & Calculated Values of Chi-Square & Diff. \\
\hline SLS1 & 99 & 113 & 133 & 20 \\
SLS2 & 99 & 113 & 17 & $(96)$ \\
SLS3 & 99 & 113 & 205 & 92 \\
SLS4 & 113 & 38 & $(75)$ \\
SLS5 & 99 & 113 & 175 & 62 \\
SLS6 & 99 & 113 & 98 & $(16)$ \\
LS1 & 99 & 113 & 137 & 24 \\
LS2 & 99 & 113 & 183 & 70 \\
\hline
\end{tabular}




\begin{tabular}{lllll}
\hline & Df. & Critical Values of Chi-Square & Calculated Values of Chi-Square & Diff. \\
\hline LS3 & 99 & 113 & 175 & 62 \\
NPS2 & 99 & 113 & 114 & 1 \\
NPS3 & 99 & 113 & 166 & 52 \\
ELS & 99 & 113 & 128 & 15 \\
\hline
\end{tabular}

i. The Diff. is the difference between the Calculated Values and the Critical Values (read in the Chi-Square table at 5\%).

ii. If Diff $>0$ there is statistically significant evidence to conclude that the distribution of climate change-related risks perception is similar for stakeholders.

iii. If Diff $<0$ there is statistically significant evidence to conclude that the distribution of climate change-related risks perception is different for stakeholders.

iv. The values between parenthesis are negative values.

\subsubsection{Climate Change Information Sources Used by Florida Key Stakeholders}

The information sources include national agencies, private companies, and non-profit organizations (Table 3). The three most used information sources were the National Oceanic and Atmospheric Administration (NOAA) (28 percent), Pew Foundation (14 percent) and ESRI (14percent). However, more than four stakeholders (34.5 percent) acquired information from NOAA and LIDAR, more than four (34.5 percent) obtained data from the Pew Foundation, CPWI, ESRI, and less than 2 (31 percent) acquired information from WM, SPM, SRCOS, AMB, CIRICS, MS, WC, CNN, and HLN (Table 4).

Table 4. Climate and Weather-Related Information, Data, and Decision Systems that Assist Stakeholders in Operational and Strategic Decision Making.

\begin{tabular}{lll}
\hline Number & Network Coding & Description \\
\hline 1 & ABM & Australian Bureau of Meteorology \\
2 & CIRICS & [Columbia University] International Research Institute for Climate and Society \\
3 & CNN & Cable News Network \\
4 & CPWI & Climate progress website information \\
5 & ESRI (for GIS) & Environmental Systems Research Institute, Inc. \\
6 & HLN & Headline News \\
7 & LIDAR & Light Detection and Ranging \\
8 & MS & Monitoring stations \\
9 & NOAA & National Oceanic and Atmospheric Administration \\
10 & Pew & Pew Foundation \\
11 & SPM & Smoke Plume modeling \\
12 & SRCOS & State/Regional climate office sources \\
13 & WM & Weather Modeling \\
\hline
\end{tabular}

Applying the Chi-Square test on the frequency use of information sources by stakeholder, revealed that stakeholders SLS1, SLS5, SLS6, LS1, LS3, NPS2, NPS3, ELS are those who were sharing similar information sources with one another, directly or indirectly (see Table 5).

Table 5. Results of a Chi-Square Test of Homogeneity among Stakeholders in the use of Information Sources.

\begin{tabular}{|c|c|c|c|c|}
\hline & Df. & Critical Values of Chi-Square & Calculated Values of Chi-Square & Diff. \\
\hline SLS1 & 99 & 113 & 180 & 67 \\
\hline SLS2 & 99 & 113 & $\mathrm{~N}$ & $\mathrm{~N}$ \\
\hline SLS3 & 99 & 113 & $\mathrm{~N}$ & $\mathrm{~N}$ \\
\hline SLS4 & 99 & 113 & $\mathrm{~N}$ & $\mathrm{~N}$ \\
\hline SLS5 & 99 & 113 & 421 & 308 \\
\hline SLS6 & 99 & 113 & 296 & 183 \\
\hline LS2 & 99 & 113 & $\mathrm{~N}$ & $\mathrm{~N}$ \\
\hline LS3 & 99 & 113 & 421 & 308 \\
\hline NPS2 & 99 & 113 & 175 & 62 \\
\hline NPS3 & 99 & 113 & 150 & 37 \\
\hline ELS & 99 & 113 & 233 & 120 \\
\hline
\end{tabular}

i. If Diff $>0$ there is statistically significant evidence to conclude that the distribution of information sources is similar for stakeholders ii. If Diff $<0$ there is statistically significant evidence to conclude that the distribution of information sources is different for stakeholders The Ns mean that the values are not defined.

\subsubsection{Synthetic Results of Survey Analysis}

By crossing the identified stakeholders who were sharing similar information sources with those stakeholders who shared equal perception levels about climate change impacts, the researchers end up with seven stakeholders SLS1, SLS5, LS1, LS3, NPS2, NPS3, and ELS. The results of the chisquare test analysis on both Information Sources and 
Perception Levels showed that these stakeholders were statistically significant in sharing similar information sources and similar perception level about the climate change risk.

\subsection{Social Network Analysis}

According to [20], centrality is relevant to the way groups are organized to find solutions to certain types of problems. The authors used two measures of centrality in this study, betweenness centrality (which quantifies the number of times a node is acting as a bridge along the shortest path between two other nodes), and eigenvector centrality (which is a measure of the influence of a node in a network).

In this study, betweenness was used, as a measure for quantifying the level of control of a stakeholder concerning communication or sharing knowledge, among other stakeholders in a social network. Eigenvector centrality assigns relative scores to all nodes in the network based on the concept that connections to high-scoring nodes contribute more to the score of the node in question than parallel connections to low-scoring nodes. The following diagrams were created using data from the 12 key stakeholders who participated in the survey.

This study had two kinds of node(s): 1) the red, which represents the different stakeholders in the Florida climate network, and 2) the blue, which represents the Florida Climate and Weather-related information, data, and decision systems that assist stakeholders in operational and strategic decision making (Figure 4, see Appendix). The blue also represents the indices to measure the importance of the climate-related information or data for stakeholders (Figures 5-11, see Appendix). Table 6-7 shown the measures of the Social Network Analysis.

Table 6. Key Stakeholders Versus Climate-Related Information Sources.

\begin{tabular}{|c|c|c|c|c|c|c|c|c|c|c|c|c|c|c|}
\hline & NOAA & LIDAR & Pew & CPWI & ESRI & WM & SPM & SRCOS & ABM & CIRICS & MS & WC & $\mathrm{CNN}$ & HLN \\
\hline SLS1 & 1 & & & & 1 & 1 & 1 & & & & & & & \\
\hline \multicolumn{15}{|l|}{ SLS2 } \\
\hline \multicolumn{15}{|l|}{ SLS3 } \\
\hline \multicolumn{15}{|l|}{ SLS4 } \\
\hline SLS5 & 1 & & & & & & & 1 & 1 & 1 & & & & \\
\hline SLS6 & 1 & 1 & 1 & 1 & 1 & & & & & & 1 & & & \\
\hline \multicolumn{15}{|l|}{ LS2 } \\
\hline LS3 & 1 & & & & & & & & & & & 1 & 1 & 1 \\
\hline NPS2 & 1 & & 1 & & & & & & & & & & & \\
\hline NPS3 & 1 & & 1 & & 1 & & & & & & & & & \\
\hline ELS & 1 & 1 & 1 & 1 & 1 & & & & & & & & & \\
\hline
\end{tabular}

Table 7. Mode Cohesion Measures for the Climate Stakeholder Dataset.

\begin{tabular}{lllllll}
\hline & Density & Avg. Distance & Radius & Diameter & Fragmentation & Transitivity \\
\hline Sheet1 & 0.159 & 2.745 & 2.000 & 4.000 & 0.342 & 0.656 \\
\hline
\end{tabular}

NOTE: If fragmentation is $>0$, the graph is disconnected. All measures based on lengths of geodesics are computed within components. Density is the number of ties divided by $n * m$, where these are respectively the number of rows and cols in the matrix. Avg Dist is the average geodesic path length in the bipartite graph, within components. Radius is the smallest eccentricity in the bipartite graph, within components. Diameter is the length of the longest geodesic in the bipartite graph, within components. Transitivity is the no. of quadruples with 4 legs divided by no. with 3 or more legs, in bipartite graph. Norm Dist is Avg Dist divided into minimum possible in bipartite graph of given node-set size

\subsubsection{Centrality of the Climate-Related Information Importance}

According to [21], conceptually, centrality captures the extent to which a focal actor occupies an essential position of prestige and visibility. In this paper, the use of two centrality approaches was attempt: the betweenness centrality and the eigenvector centrality. Typically, being at the center of things is viewed as a good thing. UCINET 6 was used to draw the diagrams and conduct the network analysis. Figure 5 shows the complete 2-mode affiliation matrix generated with NetDraw. ${ }^{3}$ In the following diagram, the blue squares represent the measures of importance regarding climaterelated information, the red circles represent the stakeholders who participate in the network, and a line between a square

3 NetDraw software was used, for all the Figures in this paper. and a circle indicates that this particular climate-related information or data is, in fact, essential for that specific stakeholder. Figure 5 shows that climate-related information is vital to all stakeholders except the NPS1 (which did not respond to any of the survey questions).

\subsubsection{Stakeholders Patterns of Secure Information or Data}

The Betweenness Centrality

Betweenness centrality captures how stakeholders control or mediate the relationships between pairs of stakeholders that are not directly connected. In this paper, the authors state that the betweenness is the extent to which a particular stakeholder lies between the various other stakeholders in the network. Therefore, the betweenness centrality measures the degree to which different stakeholders lie on the shortest geodesic path between pairs of stakeholders in the network. Therefore, this measure is an essential indicator of control of 
information exchange, or resource flows, within a system. The stakeholder with high betweenness plays a critical 'broker' or 'gatekeeper' role with a potential dominance over others (Figure 6). It may extract 'service charges' and isolate other stakeholders or prevent contacts with stakeholders. Such a stakeholder thus has a significant influence on the flow of information in the network [22].

When the measure of betweenness centrality is greater than three (Figure 7), the stakeholder LS1 is disconnected from the network because it doesn't have a link with any stakeholders who have more than three relationships with the measures of climate-related information importance. These measures are also increasingly important as the number of links is greater with stakeholders. In this study, all measures of climate-related information importance have more than three links with stakeholders.

When there is a betweenness centrality that is greater than four, the stakeholder SLS1 has the highest betweenness; it plays a role with potential for control over other stakeholders because it has more than four connections with other stakeholders, and it has more than four links with the measures of climate-related information importance. The stakeholders who have a direct or indirect relationship with SLS1 are in the network. However, stakeholders SLS2, SLS6, LS2, and NPS3 are disconnected, from the network, and regarding measuring stakeholders' perceptions about climate change impacts, the IFCCB (Impact of Florida's climate change on business) index indicates reduced importance in the network. The network would be comprised, of the following stakeholders: SLS1, SLS4, SLS5, LS3, NPS2, and ELS (Figure 8).

The Eigenvector Centrality

The eigenvector centrality is a measure of the influence of a node in a network. It assigns relative scores to all nodes in the network based on the concept that connections to highscoring nodes contribute more to the score of the node in question than similar connections to low-scoring nodes. The eigenvector centrality is one method of computing the "centrality," or relative importance, of each node in a graph. The assumption is that each node's centrality is the sum of the centrality values of the nodes with that it is connected. The nodes are drawn with a radius proportional to their centrality (Figure 9).

When the eigenvector centrality is greater than three (Figure 10), the stakeholder LS1 is, as in Figure 7, out of the network because it doesn't have a link with any stakeholders who have a score higher than three and have connections with the measures of climate-related information importance. These rules are essential, as they have a high score, and they must have links with stakeholders who have a high score. The results show that all measures of climate-related information importance were having a score higher than three, have relationships with stakeholders who have a rating higher than three. When the eigenvector centrality is more significant than four, the stakeholder SLS1 has the most influence over other stakeholders; it has the highest eigenvector centrality score, and it is connected, with more than four measures of climate-related information importance, which have scored higher than four. The stakeholders that have a direct link with SLS1 are SLS5, LS3, and ELS, and those who have an indirect relationship with SLS1 are SLS3, SLS4, and NPS2. The stakeholders that are directly or indirectly connected, with SLS1 are in the network. However, the following stakeholders SLS2, SLS6, LS2, and NPS3 are disconnected, from the network, and the IFCCB measure also is not perceived as necessary for the network. The network is composed of the following stakeholders: SLS1, SLS4, SLS5, LS3, NPS2, and ELS (Figure 11).

The two measures of centrality (betweenness and eigenvector) in the SNA have allowed the research team to identify Florida stakeholders' patterns of acquiring climaterelated information or data. The stakeholders tend to gravitate to those who have more influence to secure such information. Also, the stakeholders attach value to almost all of the measures of the importance of climate-related information. Ultimately, based on the results of the survey and of the SNA, the authors would state that despite the relative good dynamic of social networks among Florida stakeholders, there is a likelihood that certain stakeholders would have different information sources $(30.97 \%$ of stakeholders) and different awareness levels $(20.74 \%$ of stakeholders), and then different climate-related impact perceptions $(29.60 \%$ of stakeholders). These stakeholders could have corresponded to those who are not connected, to the Florida stakeholders' social networks.

\subsubsection{Synthetic Results of the Social Network Analysis}

By using the Betweenness and Eigenvector approaches on the information sources, the study concludes that stakeholders SLS1, SLS5, SLS6, LS1, LS3, NPS2, NPS3, and ELS were sharing similar information sources about climate change. The same procedure was applied, to the perception levels. The process revealed that stakeholders SLS1, SLS3, SLS4, SLS5, LS3, NPS2, and ELS were sharing similar perception levels about climate change risk.

The Social Network Analysis outcomes were given, after crossing the result on information sources with those on perception levels. These show that stakeholders SLS1, SLS5, LS3, NPS2, and ELS, would constitute the closed Network of those stakeholders who were sharing both similar information sources and similar perception level about the climate change risk.

\subsubsection{Synthetic Outcomes of Survey Analysis and Social Network Analysis}

By crossing the finding of the Survey Analysis with those of the Social Network Analysis, the research team identified the pattern of stakeholders represented by SLS1, SLS5, LS3, NPS2, and ELS as the accurate closed network. The authors are comfortable to state that the Florida critical stakeholders referred to similar information sources about climate change data. 


\subsection{Potential Economic and Policy Interest of This Research}

\subsubsection{Frequencies of Information Sources Use and Willingness to Pay}

During the study period, 13 organizations, representing the organizations providing and storing climate and weatherrelated information or data, and 13 institutions, allude to the local, regional and nonprofit stakeholders which search for, and use, climate-related data (see Tables as mentioned earlier 1 and 3 ). The sources providing climate-related information to the most stakeholders had dominance in the Florida climate network. Based on the previous Figure 4, NOAA, Pew, and ESRI (GIS) are the most prevalent providers of climate-related information to local and regional stakeholders. Eight stakeholders acquired information from NOAA, and four stakeholders obtained data from Pew and
ESRI (GIS) respectively. The stakeholders who seek out climate-related information, actively and continuously, are the following: SLS1, SLS5, SLS6, LS1, LS3, NPS2, NPS3, and ELS. However, the stakeholders SLS2, SLS3, SLS4, and LS2 do not refer to any information sources for climaterelated information.

The willingness to pay for climate change-related services, sustainability strategies, and forecasting information, is shown in Figure 12 . At least $14.3 \%$ of key stakeholders are likely to spend less than $\$ 10,000$ for climate services, and another $14.3 \%$ of principal stakeholders would be willing to pay between $\$ 50,000$ and $\$ 100,000$ for sustainability strategies. The frequency of climate change information service's use is $57.1 \%$ of the stakeholders on a monthly or quarterly base. Also, the sustainability services use rate is $28.6 \%$ for the annual, and $14.3 \%$ for annually or higher.

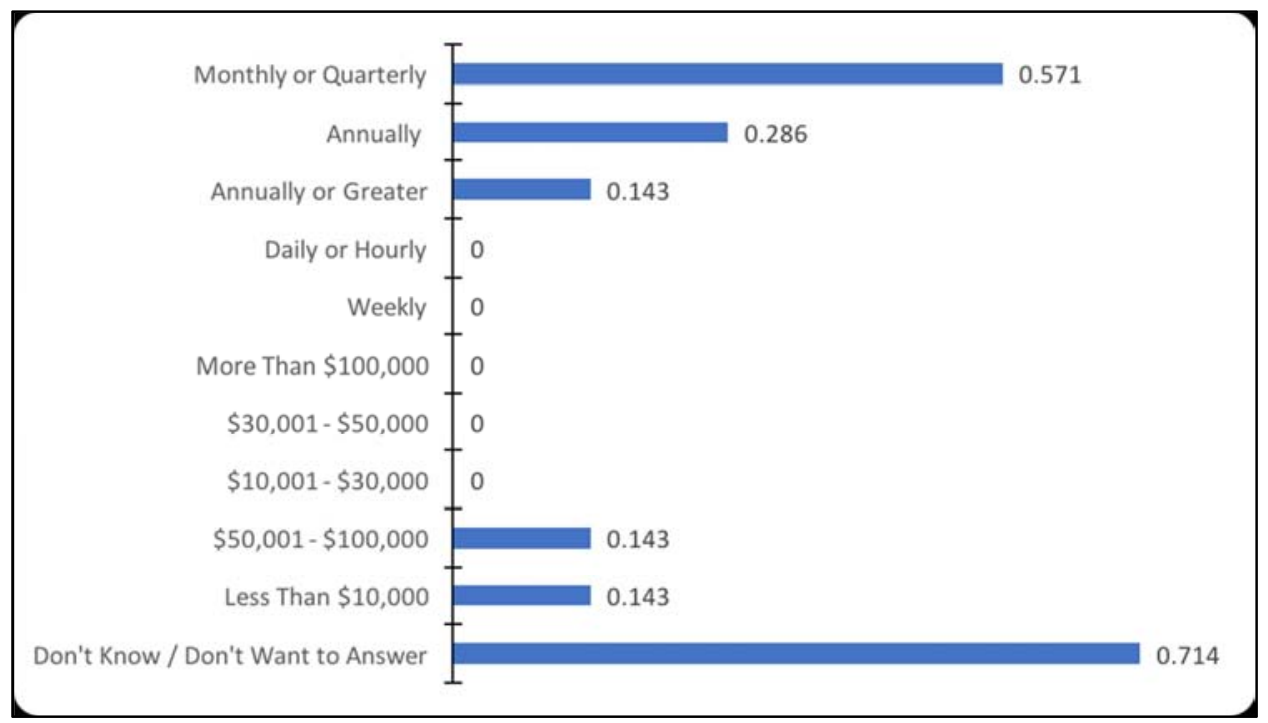

Figure 12. Florida key stakeholders' frequencies of use and willingness to pay climate change services.

\subsubsection{Synthetic Outcomes of Survey Analysis and Social Network Analysis}

The research team provided the stakeholders' comments, proposals, and their responses to the policies they are concerned about it and the need for policies. Hence, some of the stakeholders' comments and proposals about climate change related policies are reported following three categories: regarding their concerns, some stakeholders stressed that their professional work has involved waterrelated public policy, including emergency management. as a plan for the future of their businesses, the stakeholders reported that issues of climate and weather were on top of their priority. Others mentioned that the monitoring of short and long-term climate and weather trends for effect on wildfire danger, effects on trees and forests were a high level of concern for their businesses. These businesses were actively engaged in state and federal level air and Ozone quality monitoring. Some respondent comment on Climate change litigation, coal plants and renewable; those stakeholders reported that there is a connection between the
El Niño-Southern Oscillation (ENSO) phase and wildfire potential in Florida. These stakeholders suggested that policies can help guide seasonal outlooks for wildfire activity. Also, respondents mentioned, in term of infrastructure, the development of rainy days alternative routes due to flooding and roads being washed out. Early morning fog is a problem and has led to the installation of strobe lights on each bus. Accordingly, businesses have installed GPS units on all currents buses and have planned to install on all new buses as they were purchased. Stakeholders have settled hurricane plans to implement when needed and affects the environments (river and Bay) that help manage hazards.

Furthermore, some stakeholder comments on the questions related to policies that might negatively impact their business: some reported that changes to state and federal air quality regulations that would impact the ability to conduct prescribed burning. Also, that standards of Performance for Greenhouse Gas Emissions for New Stationary Sources, Electric Utility Generating Units might change. Thus, they mentioned that more must be done on climate change impact 
denial. Some others reported that limits on avenues to promote healthy forests would be negatively impactful, as well as any policies that resulted in excessive drought and other harmful conditions. Stakeholders asserted that business-as-usual, has little to no consideration regarding Florida's future 50 years from now. The same respondents stressed that policies which ignore the science and data of climate change are the worst thing that can happen. Unfortunately, climate change scientists concentrate on worst-case scenarios that scare the public and politicians. Finally, stakeholders expressed their need for realistic information, in order for the public to understand and get onboard with those engage in climate risk mitigation.

Lastly, the research team provided the stakeholders' suggestions about the policies that they would like to see policy-makers develop to positively impact their businesses, as follows: including the need to stop new coal plants, retire existing ones; and develop renewable energy especially liquid fuels, higher vehicle efficiency, solar and hot water electric. The stakeholders supported that the most beneficial would be policies that do not exacerbate drought, increasing wildfire potential. Keeping a climate which would help sustain healthy forest ecosystems is important. Policies promoting efforts to keep forest ecosystems healthy using less intense prescribed fire, as well as other measures to prevent the potential for large, destructive, and carbon releasing wildfires would seem to be helpful. Better public outreach on climate impacts, especially costs, to citizens and local governments. Respondents mentioned that the state of Florida should have a coastal and ocean policy to determine, plan for and address potential impacts of climate change, both environmentally, socially, and fiscally [23].

\section{Discussion}

Through surveys analysis and SNA approach, the research team observed a keen awareness on the part of decisionmakers and stakeholders regarding potential effects of climate change in Florida. Many organizations shared specific requests and pointed to specific agencies that have produced and disseminated useful, up-to-date, and state-ofthe-art research, analysis, tools, and predictions. However, some stakeholders may remain vulnerable regarding climate change impacts because they are disconnected from the climate learning network and do not share any information with other stakeholders.

SNA has made significant contributions to a variety of fields including sociology, social psychology, anthropology, epidemiology, management studies [24], and terrorist network studies [25]. Application of the SNA technique to mapping climate impact perceptions, and to analyzing the relationships (ties) among the stakeholders regarding climaterelated information acquisition, are relatively new according to [26-27]. For example, questions such as: "What Climate and Weather-related information, data, and decision systems do you have access to that assist you in operational and strategic decision making?" are used to determine the relationships among climate issues actors (information sources and other stakeholders). The novelty of this study is not only the two-stage approach but also the mapping of climate impact perceptions among Florida critical stakeholders involved in climate-related issues.

The use of small size sample of respondents for the survey poses difficulty in achieving statistical inference. Despite the fact that the survey respondents were spread across the state of Florida, this study's sampling encountered the limitation of the size since the research team faced funding and time constraints. Future studies are needed to confirm these results and to examine efficacy and feasibility of the research procedure and hypothesis, with large sample size. As a result of this study, the respondents are perhaps not likely to be representative of stakeholders involved in working with climate-related data and information, on a broader networking scale. The conversion of qualitative data to quantitative may cause some loss of data. Also, the SNA arbitrariness in the establishment of the connectivity threshold used to create the network may be subject to debate. Despite these limitations, the results are representative of stakeholders who are interested in climate impacts and are most likely to network closely on this issue. Qualitative responses from the survey questionnaires offer a valuable contextualization of stakeholder's climate impact perceptions, which, when combined with quantitative and the SNA results, provide a useful indication of the types of questions to pursue in future studies. In addition to these strengths, the relatively low costs associated with the survey, and the effectiveness of the data collection method, also provide further benefits. Lastly, the survey implementation is not time-consuming, when compared with other ways. The insights gained from both the survey and social network analysis approaches can help to construct inter-organizational networks and help us to understand their inter-relationships better [28].

\section{Conclusions}

Multi-sectoral collaboration involves creating new forms of relationships among organizations and local, regional stakeholders to foster linkages and trust that would enable and accelerate coordination in climate-related risk's management in Florida. The state government agencies could provide incentives and information to promote multi-sectoral collaborations. The idea of interdependence has long been at the heart of organization design in complex environments. Despite the growing literature on these issues, there has been relatively little formal investigation as to the extent to which interdependency among stakeholders can influence organizational adaptation over time in dynamic environments [29]. This research represents a modest contribution towards better understanding of how organizational design can be used to help track the inter-organizational coordination among climate data stakeholders (e.g., valid response and recovery operations, among other sectors) [30]. 


\section{Acknowledgements}

The authors would like to express their sincere thanks to the Florida State University Center for Oceanic Atmospheric Prediction Studies (FSU COAPS), the Southeast Climate Consortium (SECC), and the National Oceanic and Atmospheric Administration (NOAA) Regional Integrated Science and Assessments (RISA) Climate Program Office for their support on this portion of the project. The overall climate data stakeholders project involved the following steps: 1) Assessment Framework 2) Social Network Analysis 3) Decision Maker Surveys, and; 4) Key Stakeholder Interviews. The authors would like to express their gratitude to the Florida Climate Institute's (FCI's) Dr. Jim O'Brien (recently deceased), Dr. Jim Jones, Dr. Mason Mathews, Dr. Keith Ingram, and Dr. Vakaramoko Diaby for their guidance in the development of a climate data's users survey instrument and stakeholder survey questions.

\section{Author Contributions}

The authors contributed equally to conceive the purpose and the theoretical hypotheses of this study. Vassiki Sanogo and Zafar Siddiqui contributed to the background and the literature review. The three authors contributed to the research design and methodology. Vassiki Sanogo and Julie Harrington worked on the interpretation of the results, discussion, and conclusions. Julie Harrington contributed with comments and advice on the development of the paper.

\section{Conflict of Interest}

The authors have no conflicts of interest to declare.

\section{Appendix}

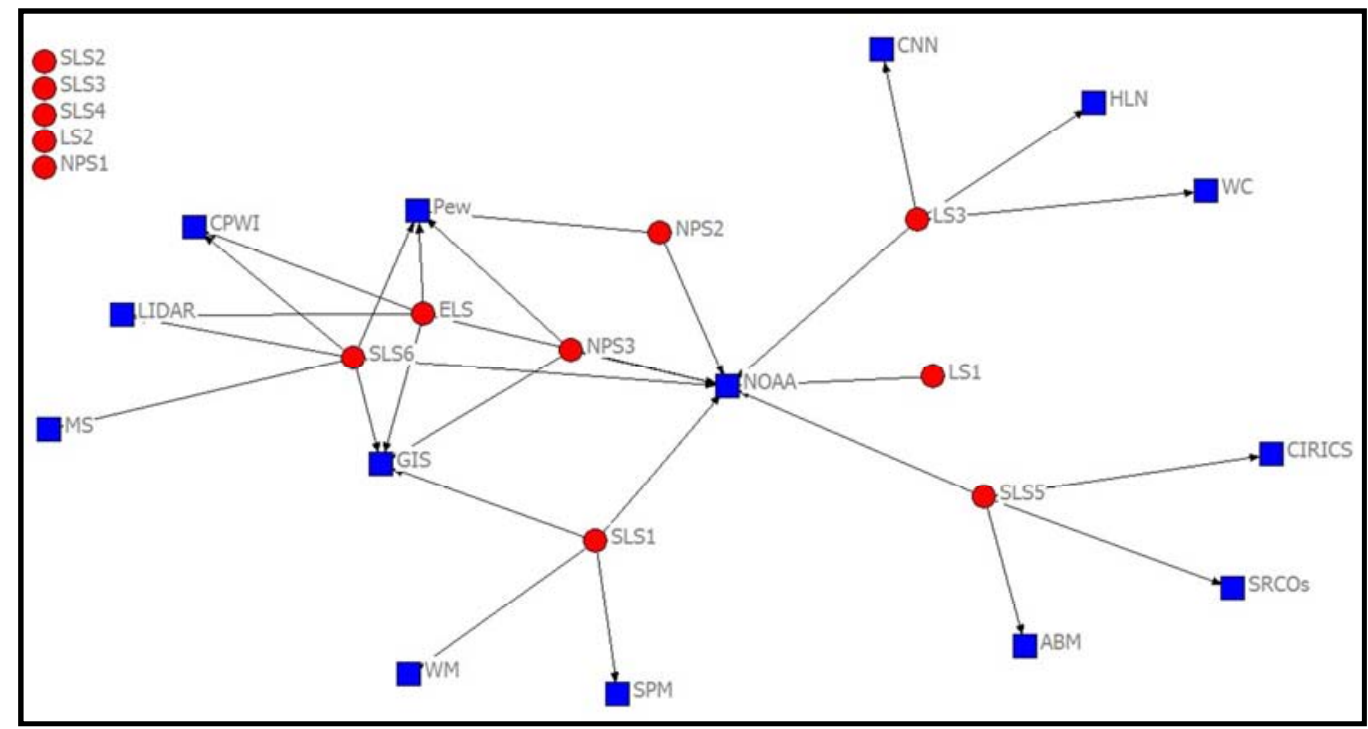

Figure 4. Stakeholders and Information Sources Analysis.

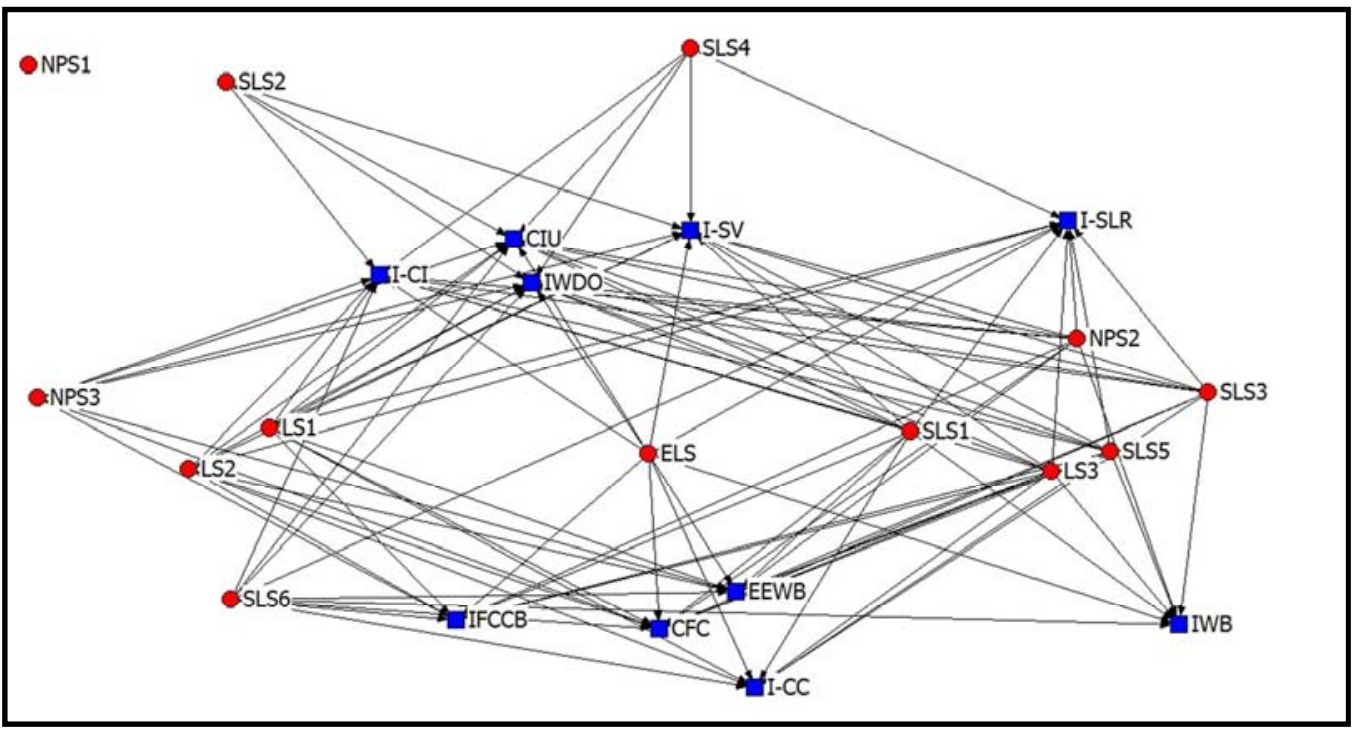

Figure 5. Issue Salience Scores. 


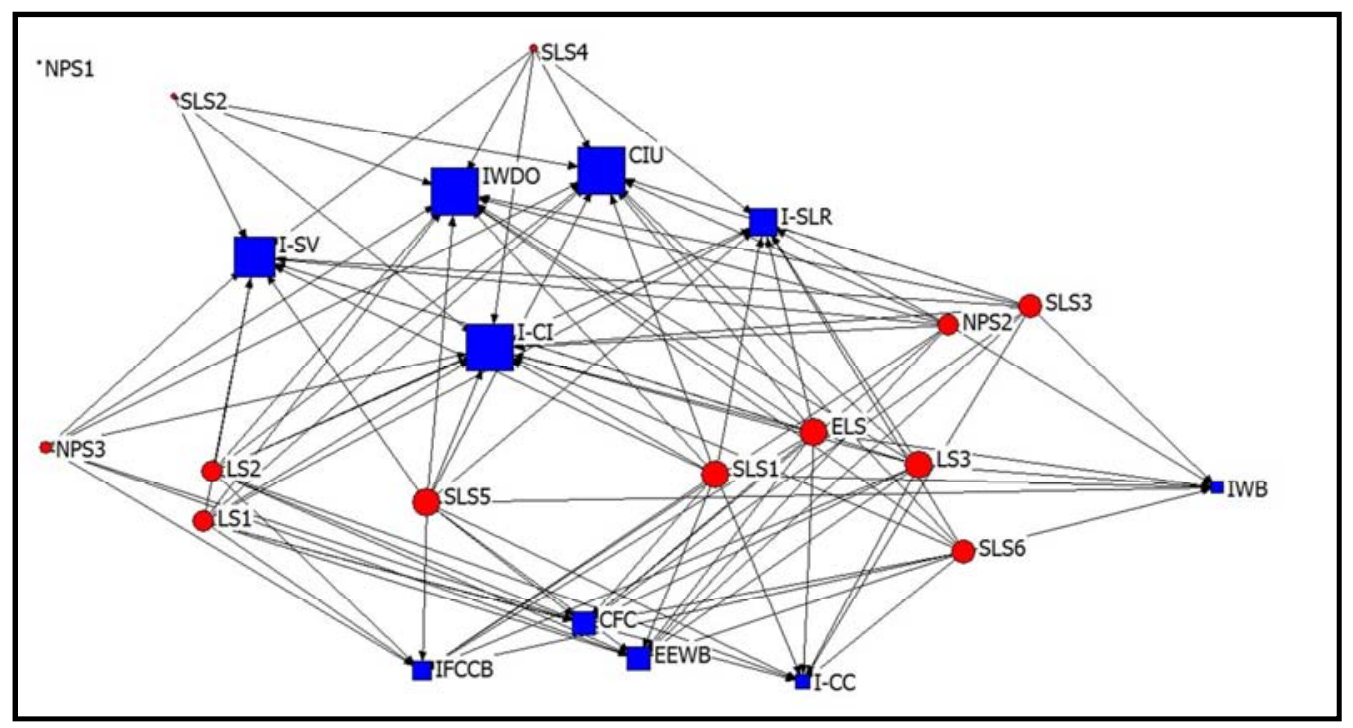

Figure 6. Issue Salience Scores - Betweenness Centrality.

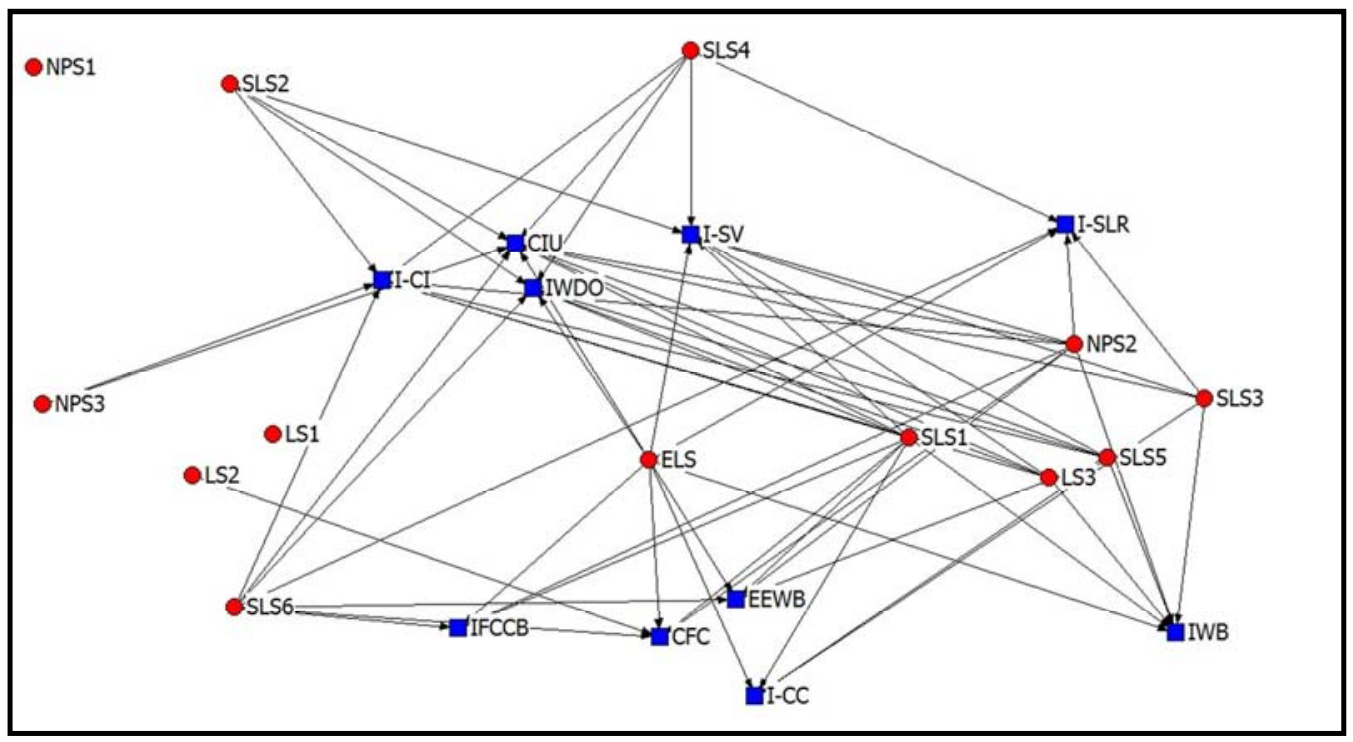

Figure 7. Issue Salience Scores- Betweenness Centrality Greater than Three.

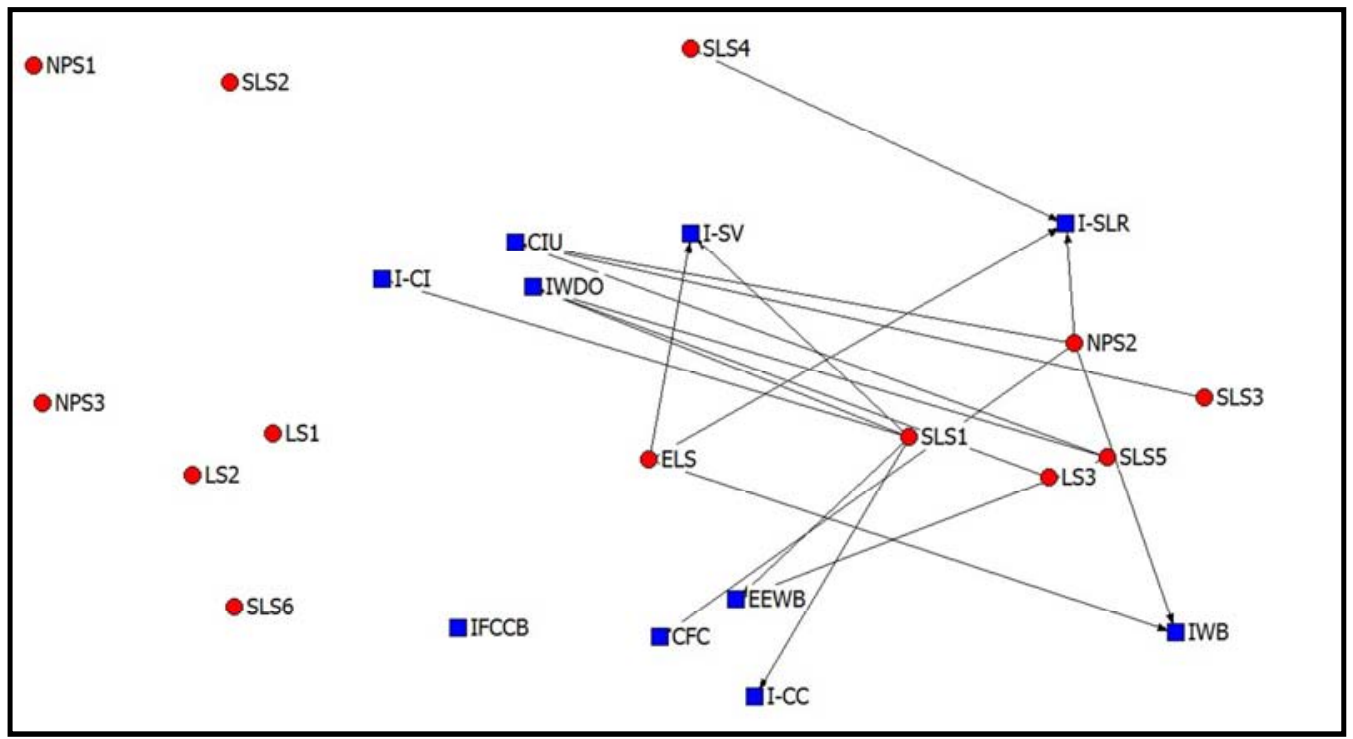

Figure 8. Issue Salience Scores-Betweenness Centrality is Greater than Four. 


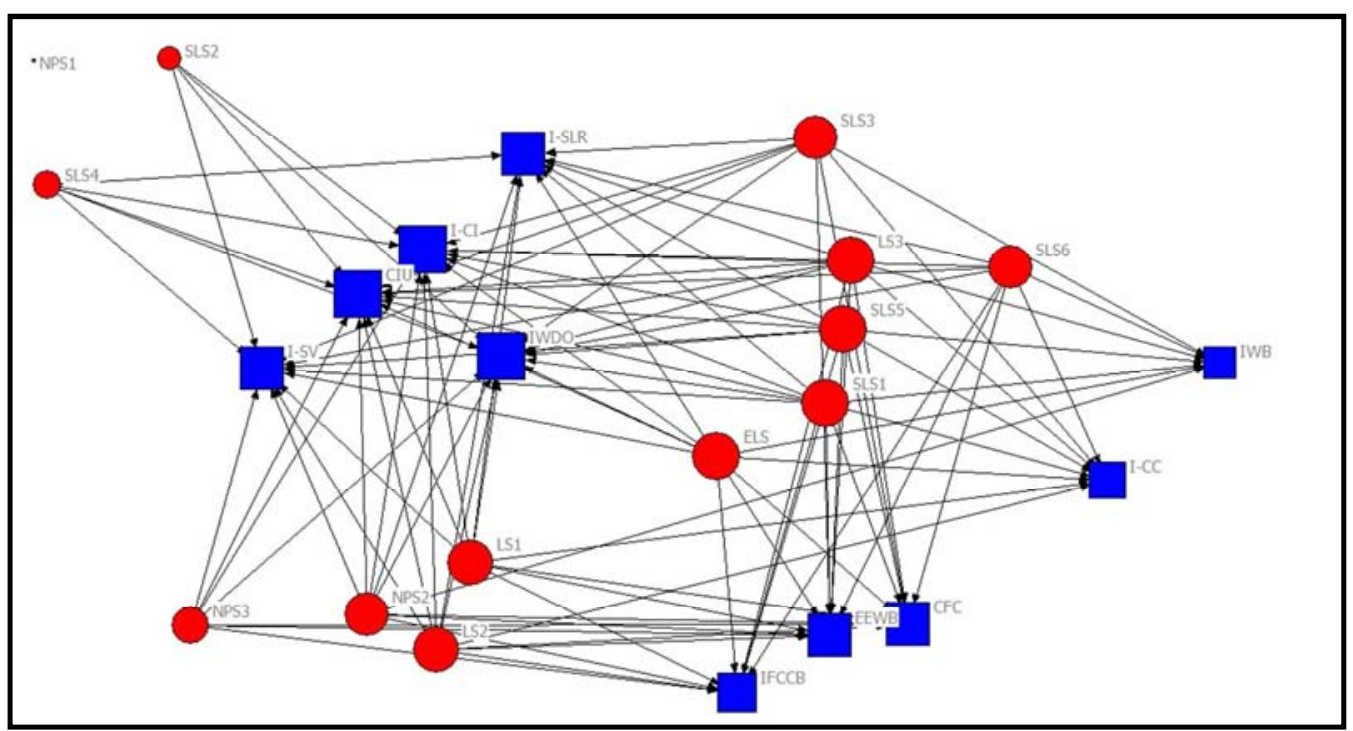

Figure 9. Issue Salience Scores - Eigenvector Centrality.

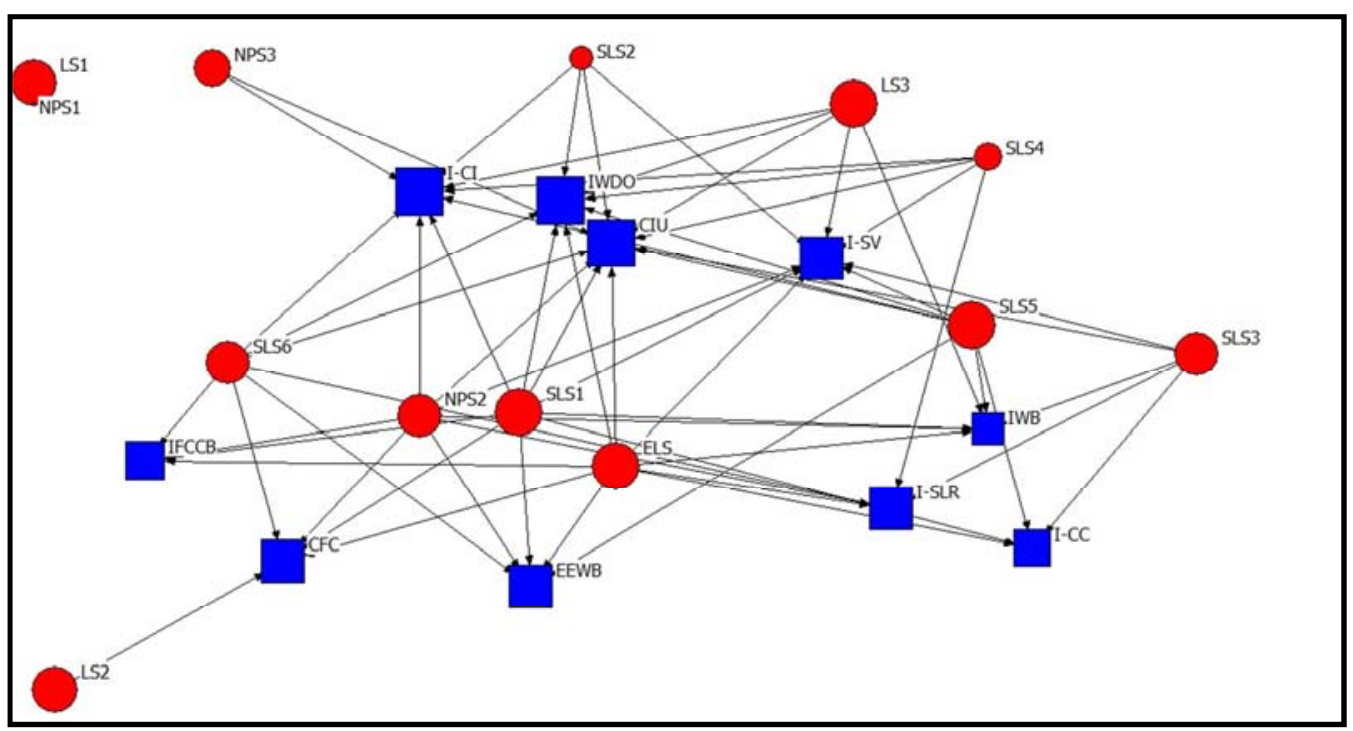

Figure 10. Issue Salience Scores - Eigenvector Centrality Greater than Three.

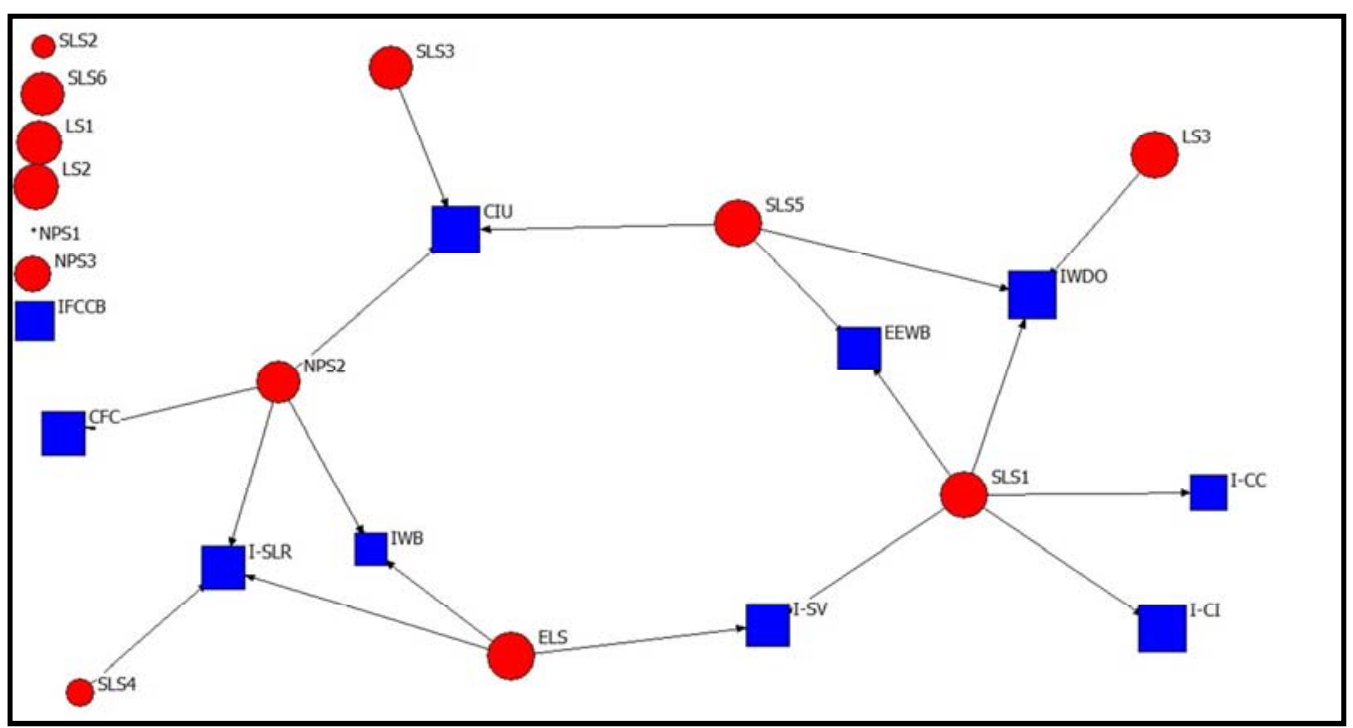

Figure 11. Issue Salience Scores - Eigenvector Centrality is Greater than Four. 


\section{References}

[1] IPCC, 2014: Climate Change 2014: Impacts, Adaptation, and Vulnerability. Part A: Global and Sectoral Aspects. Contribution of Working Group II to the Fifth Assessment Report of the Intergovernmental Panel on Climate Change [Field, C. B., V. R. Barros, D. J. Dokken, K. J. Mach, M. D. Mastrandrea, T. E. Bilir, M. Chatterjee, K. L. Ebi, Y. O. Estrada, R. C. Genova, B. Girma, E. S. Kissel, A. N. Levy, S. MacCracken, P. R. Mastrandrea, and L. L. White (eds.)]. Cambridge University Press, Cambridge, United Kingdom and New York, NY, USA, 1132 pp.

[2] IPCC, 2012. Managing the Risks of Extreme Events and Disasters to Advance Climate Change Adaptation: Field, C. B. V. Barros, T. F. Stocker, D. Qin, D. J. Dokken, K. L. Ebi, M. D. Mastrandrea, K. J. Mach, G.-K. Plattner, S. K. Allen, M. Tignor, and P. M. Midgley (Eds.) Available from Cambridge University Press, The Edinburgh Building, Shaftesbury Road, Cambridge CB2 8RU ENGLAND, $582 \mathrm{pp}$. Available from June 2012.

[3] IPCC, 2011. Renewable Energy Sources and Climate Change Mitigation: Ottmar Edenhofer, Ramón Pichs-Madruga, Youba Sokona, Kristin Seyboth, Patrick Matschoss, Susanne Kadner, Timm Zwickel, Patrick Eickemeier, Gerrit Hansen, Steffen Schloemer, Christoph von Stechow (Eds.) Cambridge University Press, Cambridge, United Kingdom and New York, NY, USA, $1075 \mathrm{pp}$.

[4] IPCC. 2007. Climate Change 2007: The Physical Science Basis. Contribution of Working Group I to the Fourth Assessment Report of the IPCC. In S. Solomon, D. Qin, M. Manning, Z. Chen, M. Marquis, K. B. Averyt, M. Tignor and H. L. Miller, eds. Cambridge, UK: Cambridge University Press. 996 pp.

[5] IPCC. 2001. Climate Change 2001: Impacts, Adaptation \& Vulnerability: Contribution of Working Group II to the Third Assessment Report of the IPCC. In J. J. McCarthy, O. F. Canziani, N. A. Leary, D. J. Dokken and K. S. White, eds. Cambridge, UK: Cambridge University Press. 1000 pp.

[6] IPCC. 1995. Climate Change 1995: The IPCC Impacts Assessment: Contribution of Working Group II to the Second Assessment Report of the IPCC. in W. J. McG. Tegart, G. W. Sheldon and D. C. Griffiths (eds.). Australian Government Publishing Service, Camberra, Australia 294 pp.

[7] IPCC. 1990. Climate Change 1990: The IPCC Impacts Assessment: Contribution of Working Group II to the First Assessment Report of the IPCC. in W. J. McG. Tegart, G. W. Sheldon and D. C. Griffiths (eds.). Australian Government Publishing Service, Camberra, Australia 294 pp.

[8] NOAA, 2007. National Climate Report. https://www.ncdc.noaa.gov/sotc/national/200713

[9] Bartels, W. L., Furman, C. A., Diehl, D. C., Royce, F. S., Dourte, D. R., Ortiz, B. V.,... \& Jones, J. W., 2013: Warming up to climate change: a participatory approach to engaging with agricultural stakeholders in the Southeast US. Regional Environmental Change, 13(1), 45-55.

[10] Bellon, M. R., Hodson, D., and Hellin, J., 2011: Assessing the vulnerability of traditional maize seed systems in Mexico to climate change. Proceedings of the National Academy of
Sciences of the United States of America, 108(33), 1343213437.

[11] Capstick, S., Whitmarsh, L., Poortinga, W., Pidgeon, N. and Upham, P., 2015. International trends in public perceptions of climate change over the past quarter century. Wiley Interdisciplinary Reviews: Climate Change, 6(1), pp. 35-61.

[12] Borgatti, S. P., and Everett, M. G. (81). Freeman, LC., 2002: UCInet for Windows: Software for Social Network Analysis. Analytic Technologies, Harvard: MA.

[13] Bostrom, A., Morgan, M. G., Fischhoff, B. and Read, D., 1994: What do people know about global climate change? 1. Mental models. Risk Analysis, 14(6), 959-970.

[14] Carolan, B. V. and Wasserman, S. J., 2014. Does parenting style matter.

[15] Croft, D. P., James, R. and Krause, J., 2008. Exploring animal social networks. Princeton University Press.

[16] Cross, R. L. and Parker, A., 2004. The hidden power of social networks: Understanding how work really gets done in organizations. Harvard Business Review Press.

[17] Dwayne E. P. and Coauthors, 2004: Data Management in Support of Environmental Monitoring, Research, and Coastal Management in Journal of Coastal Research, 45: 9-16.

[18] Freeman, L. C., 1977: A set of measures of centrality based on betweenness. Sociometry, 35-41.

[19] Hanneman, R. A., 2001: The prestige of Ph. D. granting departments of sociology: a simple network approach. Connections, 24(1), 68-77.

[20] Kleiner, B. M., Hettinger, L. J., DeJoy, D. M., Huang, Y. H. and Love, P. E., 2015. Sociotechnical attributes of safe and unsafe work systems. Ergonomics, 58(4), pp. 635-649.

[21] Kohut J. and Coauthors, 2012: Evaluation of two algorithms for a network of coastal HF radars in the Mid-Atlantic Bight in Ocean Dynamics, 62:953-968.

[22] McPhaden, J. M., and Coauthors, 1998: The Tropical OceanGlobal Atmosphere observing system: A decade of progress in Journal of Geophysical Research, 103(C7), 14,169-14,240.

[23] Mochizuki, J., Schinko, T. and Hochrainer-Stigler, S., 2018. Mainstreaming of climate extreme risk into fiscal and budgetary planning: application of stochastic debt and disaster fund analysis in Austria. Regional Environmental Change, pp. 1-12.

[24] Robert G. D. Steel and James H. Torrie, 1980 "Principles and Procedures of Statistics: A Biometrical Approach" Second Edition, pp 477-478.

[25] Shackley, S., and Deanwood, R., 2002: Stakeholder perceptions of climate change impacts at the regional scale: Implications for the effectiveness of regional and local responses. Journal of Environmental Planning \& Management, 45(3), 381-402.

[26] Tobin, G. A. and Begley, C. M., 2004. Methodological rigour within a qualitative framework. Journal of advanced nursing, 48(4), pp. 388-396.

[27] Whitehead, H., 2009. SOCPROG programs: analysing animal social structures. Behavioral Ecology and Sociobiology, 63(5), pp. 765-778. 
[28] Caetano, F. J., Oliveira, C. M., Araújo, M. F. and Rêgo, M. C., 2018. Towards Climate Change Awareness Through Distance Learning-Are Young Portuguese and Brazilian University Students Vigilant?. In Climate Literacy and Innovations in Climate Change Education (pp. 261-273). Springer, Cham.

[29] Ngo, V. D., Frank, L. D. and Bigazzi, A. Y., 2018. Effects of new urban greenways on transportation energy use and greenhouse gas emissions: A longitudinal study from Vancouver, Canada. Transportation Research Part D: Transport and Environment, 62, pp. 715-725.
[30] Steentjes, K., Pidgeon, N. F., Poortinga, W., Corner, A. J., Arnold, A., Böhm, G., Mays, C., Poumadère, M., Ruddat, M., Scheer, D. and Sonnberger, M., 2017. European Perceptions of Climate Change (EPCC): Topline findings of a survey conducted in four European countries in 2016. 